\title{
Pre-1997 Trends in Welfare and Food Assistance in a National Sample of Families
}

\author{
Parke E. Wilde, Sandra Hofferth, Stephen Stanhope, Mary Noonan, \\ and Nancy Collins
}

Both the Food Stamp Program (FSP) and Aid to Families with Dependent Children (AFDC) saw unprecedented caseload growth from the late 1980s until 1994, followed by caseload declines in the following years. These rapid caseload declines are attributed to changing macroeconomic conditions and to substantial changes in program design. First, in the early 1990s, states applied for waivers from federal welfare program regulations, which allowed them more freedom to experiment with welfare reforms. Then, in 1996, Congress redesigned the federal safety net for low-income Americans through the Personal Responsibility and Work Opportunity Reconciliation Act (PRWORA).

These real-world developments suggest some research questions. Do macroeconomic conditions affect FSP caseloads and cash welfare program caseloads in the same way? Do policy changes in cash programs affect participation in the FSP, which serves a partly overlapping population? Because caseload changes depend directly on the rates at which people enter and exit each program, it is useful in answering these questions to investigate participation transitions at the individual level.

This paper uses data from the Panel Study of Income Dynamics (PSID) to investigate participation transitions from year to year during the "waiver period," from 1989 to 1996. The distinctive feature of the approach here is that it considers all possible transitions at the individual level among three participation states $-A F D C$ (with or without FSP), FSP Only, and Neitherrather than treating each program separately.

Parke E. Wilde is with the Food and Rural Economics Division, Economic Research Service, USDA. Sandra Hofferth is with the Institute for Social Research, University of Michigan. Stephen Stanhope is with the Program in Financial Engineering and the Program in Applied Economics, University of Michigan. Mary Noonan and Nancy Collins are with the Population Studies Center, University of Michigan.
This investigation provides a baseline for future work using PSID data to study the impact of the 1996 welfare reforms.

\section{Changes to the Food Stamp Program and Cash Welfare Programs}

In many cases, the 1996 welfare reform law implemented on a broader scale what states had already begun to implement through waiver policies. Starting in the early 1990s, states were given the option of requesting waivers to federal AFDC rules regarding eligibility and benefits. The types of cash program waivers that are central to the following analysis include Time Limits, which either terminated or reduced a recipient's benefit level after a specified period, Work Requirements, which required non-exempt recipients to participate in a work activity after a specified period of time as a condition of continued benefit receipt, Expanded Earnings Disregard, which increased the amount of earnings disregarded in determining the level of the AFDC grant, Family Caps, which reduced or eliminated additional benefits for children who were conceived while the mother was receiving assistance, JOBS Exemptions, which provided either the traditional exemption for mothers of children under age six, an exemption for mothers of children from six months to three years, an exemption for mothers of children from birth to six months of age, or no exemption, and Work Sanctions, which provided either the traditional (mild) sanctions for violations of work requirements or more severe sanctions. We consider three categories of more severe sanctions, in increasing order of severity: partial sanctions for the first violation and for recurrent violations ("partial/partial"), partial sanctions for the first violation and full sanctions for later 
violations ("partial/full"), and full sanctions for the first violation and for later violations ("full/full").

Time limits, work requirements, lack of exemptions for mothers of very young children, the family cap, and more severe sanctions for failure to comply with work requirements are expected to make AFDC participation less desirable and, therefore, to reduce participation by increasing exits and reducing entries. In contrast, under the expanded earnings disregard, which allows participants to keep more of their earnings, more participants may remain on the rolls even as they gain employment. Thus, it should reduce exit and increase entrance.

The effects of welfare waivers on cash program participation have most commonly been studied using state-level data (Council of Economic Advisors, Figlio and Ziliak). A recent exception using less aggregated data from the Current Population Survey (CPS) is Moffitt, who observes: "Aggregate data at the state level necessarily gloss over the differences within a state's population and do not permit analysis of the groups most likely to be affected by welfare reform." Gleason, Schochet, and Moffitt use panel data from the Survey of Income and Program Participation to study FSP caseload growth in the early 1990s. The study attributes the caseload growth to a fall in exit rates rather than a rise in the number of families beginning to receive food stamps.

The 1996 welfare reform act made some direct changes to the FSP, but in the waiver period the biggest effects of policy changes on FSP participation are expected to be indirect, as a consequence of the more substantial changes to cash welfare programs. Using state-level data, Wallace and Blank find that cash programs and the FSP are both affected by policy changes, but there remains substantial uncertainty about the magnitude of these policy effects. We know of no previous study of individual-level transitions across the three participation states addressed in this paper.

\section{Data}

The PSID is a longitudinal survey of a representative sample of U.S. men, women, and children and the families in which they reside conducted annually during the spring. The data set contains monthly histories of receipt of welfare, food stamps, housing assistance, and other public and private transfers, plus annual income and a history of employment, marriage, and childbearing for the calendar year preceding the survey date. From 5,000 families in 1968, the study grew to over 9,000 core families in the 1996 wave since children and other sample members become respondents in their own right when they leave the original household. In the 1997 wave the PSID reduced its core sample to 6,700 and added a refresher sample of 450 immigrant families so that the sample represents the U.S. population. With appropriate use of weights, the PSID remains representative of the U.S. population for cross-sectional and longitudinal research (Fitzgerald, Gottschalk, and Moffitt).

This paper uses two different data files. First, a preliminary state-level analysisundertaken so that our results may be compared to previous research with state-level data-employs a file with eight years of data from calendar years 1989 through 1996 for fifty states and the District of Columbia, a total of 408 observations. The dependent variables in this analysis are state-year participation rates in $A F D C$ (whether or not receiving food stamps), state-year participation rates in FSP Only, and average dollars of food stamps received. These rates are calculated from the sample of weighted PSID respondent families in each state. Because of the presence of zero participation rates resulting from small sample sizes in some states, the actual rate of participation rather than its log was used (see Moffitt). The unemployment rate and the lagged rate in each state for each year were obtained from the CPS, and the maximum AFDC benefit in each year and each state for a family of three was obtained from the Green Book. We analyze the waiver policies studied in the CEA report, using the date that each waiver was implemented statewide to create our waiver variables.

Second, the main analysis of transitions is based upon observations on approximately 12,450 individuals who were ever head of a household between calendar years 1989 through 1996. Each observation consists of a pair of adjacent years beginning in calendar year 1989, a total of 48,935 paired person-years. The dependent variables are the six off-diagonals of the matrix of transitions from $A F D C$, FSP Only, or Neither to $A F D C$, FSP Only, or Neither from one year 
to the next. We also include the six transitions from these three programs into and out of the study (Missing) in order to completely describe the movements into and out of our program states. State-level unemployment rates, AFDC benefit levels, and public waiver policies are drawn from the first year of the pair of years. Race (black, Hispanic versus white, and non-Hispanic), education, age, work-limiting disability, female headship, and number of children are the demographic variables included in the model. The initial transition year is also controlled.

\section{Analysis of State-Level Data}

Before studying transitions at the individual level, we begin by estimating a typical state-level caseload model using PSID participation data. Although precise data on participation are available from administrative sources, this exercise with PSID participation data helps to bridge the gap between earlier studies using state-level data (Wallace and Blank) and the analysis of transitions below. The state-level results are summarized here briefly; tables omitted here are available from the authors.

We obtain a positive relationship between the monthly AFDC benefit for a family of three and participation in $A F D C$, as do the Council of Economic Advisors (CEA) and Moffitt. Even with year and state fixed effects included, we obtain the expected positive and statistically significant relationship between the expanded earnings disregard and participation in $A F D C$. In states which only exempt mothers of children six months to three years from the work requirement, cash program participation rates are lower. As in the CEA report, this finding holds only in models that do not adjust for state specific trends. Partial/full and full/full sanctions have the expected negative effects and are marginally significant in the models adjusting for state-year trends (consistent with Moffitt and the CEA). The work requirement and time limit variables have the expected negative signs before adjusting for state and year fixed effects, but do not attain statistical significance.

Few policy variables are related to participation in FSP Only at the state level. To see whether dollar amounts might be related to changes in cash assistance policies independent of participation rates, we examined the association between public waiver policies and average food stamp benefits received per recipient. In states which implemented a time limit prior to PRWORA, food stamp participants received a higher amount in food stamps. This held even upon controlling for state and year fixed effects. Presumably, such recipients are receiving lower cash benefits. As expected, in states that expanded the earnings disregard, allowing recipients to keep more of their cash assistance when they work, the average amount of food stamp benefits received was lower. This shows the close ties between cash and noncash programs. The later result is robust whether controlling for year, state, or state-year trends.

\section{Descriptive Analysis of Participation Transitions}

In the PSID sample, the weighted count $(N)$ of families participating in FSP Only grew between 1989 and 1993 (from 242 to 320), and then declined from 1993 to 1996 (to 256) (table 1, bottom panel). The descriptive analysis here focuses on comparing these two periods (table 1, rows labeled "Net change per year"). Tables of each pair of adjacent years are available from the authors. This pattern in the PSID sample is mostly consistent with more precise data from administrative sources, which show that FSP participation overall (including both participants and nonparticipants in AFDC) peaked in March 1994. One difference is that the PSID would appear to attribute the full change in FSP participation in 1989-93 to growth in the FSP Only category, whereas administrative sources show the AFDC caseload also grew rapidly during this period (by $30 \%$ from 1988-93). The PSID and administrative data agree that the participation decline in 1993-96 is about evenly split between participants in $A F D C$ (including participants in both programs) and participants in FSP Only.

Table 1 also reports results for the Missing category, which represents sampled individuals who are missing in a particular year, but who appear in the survey in another year or years. The number of transitions to and from Missing is relatively steady for the years 1989-95, but transitions to Missing increase in 1996 when the survey sample was reduced 
Table 1. Weighted Year-to-Year Participation Transitions in the PSID

\begin{tabular}{|c|c|c|c|c|c|}
\hline \multirow{2}{*}{$\begin{array}{l}\text { Years 1989-93 } \\
t+1-\text { Mean annual transitions to: }\end{array}$} & \multicolumn{4}{|c|}{$t-$ Mean annual transitions from: } & \multirow[b]{2}{*}{ Total } \\
\hline & AFDC & FSP only & Neither & Missing & \\
\hline AFDC & - & 23.50 & 36.75 & 25.50 & 85.75 \\
\hline FSP only & 31.75 & - & 83.50 & 31.00 & 146.25 \\
\hline Neither & 33.50 & 76.50 & - & 393.75 & 503.75 \\
\hline Missing & 23.25 & 27.50 & 299.50 & - & 350.25 \\
\hline Total & 88.5 & 127.5 & 419.75 & 450.25 & \\
\hline Years 1993-96 & \multicolumn{4}{|c|}{$t$-Mean annual transitions from: } & \\
\hline$t+1-$ Mean annual transitions to: & AFDC & FSP only & Neither & Missing & Total \\
\hline AFDC & - & 25.67 & 34.67 & 19.33 & 79.67 \\
\hline FSP only & 30.00 & - & 76.00 & 30.00 & 136 \\
\hline Neither & 40.33 & 87.67 & - & 285.00 & 412.97 \\
\hline Missing & 31.00 & 44.00 & 560.00 & - & 635 \\
\hline Total & 101.33 & 157.34 & 670.67 & 334.33 & \\
\hline Net change per year, 1989-93 & -2.8 & 18.8 & 84.0 & -100.0 & \\
\hline Net change per year, 1993-96 & -21.7 & -21.3 & -257.7 & -300.7 & \\
\hline$N$ in 1989 & 241 & 242 & 5,088 & 2,492 & \\
\hline$N$ in 1993 & 230 & 320 & 5,423 & 2,090 & \\
\hline$N$ in 1996 & 165 & 256 & 4,650 & 2,992 & \\
\hline
\end{tabular}

Notes: Weights sum to the sample size in the PSID (not to the population), so each entry in the transition tables represents approximately the mean annual number of individuals in the data set that make a transition from the participation state listed in the columns in year $t$ to the participation state listed in the rows in year $t+1$. The two periods 1989-93 and 1993-96 were selected because they represent a period of caseload growth and a period of caseload decline. The participation decline in 1993-96 includes some who moved from program participation to Missing in 1996, when the PSID sample size was reduced. Net change is calculated by substracting exists (column total) from entrances (row total).

as discussed above, which increases the transitions for 1993-96.

Several points may be made about the detailed transitions to and from each participation state in both periods 1989-93 and 1993-96 (table 1, top two sections). Using the 1989-93 period as our example, the large number of transitions from FSP Only to Neither (76.5) and from Neither to FSP Only (83.5) and the smaller number of transitions from $A F D C$ to Neither (31.75) and from Neither to $A F D C$ (36.75) indicate more rapid "churning" and shorter participation spells for participants in FSP Only than in $A F D C$. There are more transitions from $A F D C$ to FSP Only (31.75) than there are from FSP Only to AFDC (23.5), suggesting that FSP Only is more frequently a stepping stone on the road off cash welfare, and less frequently a stepping stone onto cash welfare.

The most interesting comparisons are between transitions during the period of participation growth (1989-93) and the period of participation decline (1993-96). In 198993, 127.5 people annually left FSP Only and 146.25 entered, for a net annual increase of 18.8 people. In 1993-96, 157.34 people annually left FSP Only and 136 entered, for a net decline of 21.3 people. The reversal in trajectory appears to be due to a small decline in the number of entrances to both $A F D C$ (85.75 to 79.67) and FSP Only (146.25 to 136) and a more substantial increase in exits from both program states (88.5 to 101.3 and 127.5 to 157.3 , respectively), which is consistent with earlier results from Gleason, Schochet, and Moffitt. The number of transitions between the two states of program participation remained steady across the two periods. Understanding the causes of these transition phenomena is the topic of the multivariate analysis in the next section.

\section{Logistic Regression Analysis of Participation Transitions}

In table 2 we show the coefficients for the state policy variables, state unemployment rate, and maximum AFDC benefit from logistic regression estimation with individ- 
Table 2. Logistic Regression Estimates for Participation Transitions

\begin{tabular}{|c|c|c|c|c|c|c|}
\hline Variable & $\begin{array}{l}\text { AFDC to } \\
\text { FSP Only }\end{array}$ & $\begin{array}{l}\text { AFDC to } \\
\text { Neither }\end{array}$ & $\begin{array}{l}\text { FSP Only } \\
\text { to AFDC }\end{array}$ & $\begin{array}{l}\text { Neither } \\
\text { to AFDC }\end{array}$ & $\begin{array}{l}\text { FSP Only } \\
\text { to Neither }\end{array}$ & $\begin{array}{l}\text { Neither to } \\
\text { FSP Only }\end{array}$ \\
\hline Unemployment rate & $\begin{array}{r}0.1216^{*} \\
(0.0697)\end{array}$ & $\begin{array}{r}-0.0679 \\
(0.0719)\end{array}$ & $\begin{array}{c}0.0347 \\
(0.0733)\end{array}$ & $\begin{array}{r}0.1435^{*} \\
(0.0644)\end{array}$ & $\begin{array}{r}-0.1727^{*} \\
(0.0454)\end{array}$ & $\begin{array}{c}0.0606 \\
(0.0412)\end{array}$ \\
\hline Maximum AFDC benefit & $\begin{array}{r}-0.0013^{*} \\
(0.0007)\end{array}$ & $\begin{array}{c}0.0003 \\
(0.0006)\end{array}$ & $\begin{array}{r}0.0024^{*} \\
(0.0007)\end{array}$ & $\begin{array}{r}0.0021^{*} \\
(0.0005)\end{array}$ & $\begin{array}{l}-0.0007 \\
(0.0005)\end{array}$ & $\begin{array}{c}-0.0003 \\
(0.0003)\end{array}$ \\
\hline Time limit & $\begin{array}{r}-0.1012 \\
(0.7943)\end{array}$ & $\begin{array}{r}1.2482^{*} \\
(0.5889)\end{array}$ & $\begin{array}{c}-0.2612 \\
(0.7981)\end{array}$ & $\begin{array}{r}-0.3048 \\
(0.5524)\end{array}$ & $\begin{array}{r}-0.1698 \\
(0.4875)\end{array}$ & $\begin{array}{r}0.7027^{*} \\
(0.3845)\end{array}$ \\
\hline Work requirement & $\begin{array}{c}-0.1743 \\
(0.5564)\end{array}$ & $\begin{array}{c}-0.2481 \\
(0.4705)\end{array}$ & $\begin{array}{r}-0.6890 \\
(0.7360)\end{array}$ & $\begin{array}{r}-0.5329 \\
(0.4034)\end{array}$ & $\begin{array}{r}-0.7836^{*} \\
(0.3768)\end{array}$ & $\begin{array}{c}-0.1264 \\
(0.3227)\end{array}$ \\
\hline Expanded earnings disregard & $\begin{array}{r}-0.2810 \\
(0.3601)\end{array}$ & $\begin{array}{c}0.0625 \\
(0.3375)\end{array}$ & $\begin{array}{r}-0.4293 \\
(0.4665)\end{array}$ & $\begin{array}{c}-0.0893 \\
(0.2775)\end{array}$ & $\begin{array}{l}1.5268^{*} \\
(0.3095)\end{array}$ & $\begin{array}{c}-0.1362 \\
(0.2260)\end{array}$ \\
\hline Family cap & $\begin{array}{c}0.2451 \\
(0.4163)\end{array}$ & $\begin{array}{r}-0.6118 \\
(0.4672)\end{array}$ & $\begin{array}{r}-0.4664 \\
(0.5156)\end{array}$ & $\begin{array}{c}0.4160 \\
(0.3586)\end{array}$ & $\begin{array}{c}0.0599 \\
(0.2535)\end{array}$ & $\begin{array}{c}-0.3725 \\
(0.2598)\end{array}$ \\
\hline OBS exe & & & & & & \\
\hline $\begin{array}{l}\text { Traditional exemption } \\
\text { Child-six mo to three yrs }\end{array}$ & $\begin{array}{c}\text { omitted } \\
-1.2886 \\
(1.4275)\end{array}$ & $\begin{array}{c}\text { omitted } \\
-1.5795 \\
(1.2379)\end{array}$ & $\begin{array}{c}\text { omitted } \\
-1.1821 \\
(1.0127)\end{array}$ & $\begin{array}{c}\text { omitted } \\
-0.5423 \\
(0.6217)\end{array}$ & $\begin{array}{c}\text { omitted } \\
0.4085 \\
(0.4819)\end{array}$ & $\begin{array}{c}\text { omitted } \\
-0.3321 \\
(0.5152)\end{array}$ \\
\hline Child-newborn to six mo & $\begin{array}{c}-0.3865 \\
(0.7817)\end{array}$ & $\begin{array}{r}-0.2572 \\
(0.6374)\end{array}$ & $\begin{array}{c}1.1263 \\
(0.7900)\end{array}$ & $\begin{array}{r}-0.3146 \\
(0.5972)\end{array}$ & $\begin{array}{r}-0.9598 \\
(0.7193)\end{array}$ & $\begin{array}{r}-0.8992^{*} \\
(0.4868)\end{array}$ \\
\hline No exemptions & $\begin{array}{r}0.6601^{*} \\
(0.3932)\end{array}$ & $\begin{array}{r}-0.3800 \\
(0.4465)\end{array}$ & $\begin{array}{c}0.5019 \\
(0.6239)\end{array}$ & $\begin{array}{r}-0.6052 \\
(0.4884)\end{array}$ & $\begin{array}{r}-0.6552^{*} \\
(0.3974)\end{array}$ & $\begin{array}{c}-0.3998 \\
(0.3415)\end{array}$ \\
\hline JOBS $\mathrm{s}$ & & & & & & \\
\hline $\begin{array}{l}\text { Traditional sanctions } \\
\text { Partial/partial }\end{array}$ & $\begin{array}{c}\text { omitted } \\
-0.3382 \\
(0.5309)\end{array}$ & $\begin{array}{c}\text { omitted } \\
0.6216 \\
(0.4522)\end{array}$ & $\begin{array}{c}\text { omitted } \\
0.5007 \\
(0.5462)\end{array}$ & $\begin{array}{c}\text { omitted } \\
-0.2520 \\
(0.4880)\end{array}$ & $\begin{array}{c}\text { omitted } \\
-0.0383 \\
(0.3112)\end{array}$ & $\begin{array}{c}\text { omitted } \\
-0.3319 \\
(0.3405)\end{array}$ \\
\hline Partial/full & $\begin{array}{c}-0.0434 \\
(0.4822)\end{array}$ & $\begin{array}{r}-0.5175 \\
(0.5346)\end{array}$ & $\begin{array}{c}0.3130 \\
(0.6176)\end{array}$ & $\begin{array}{c}0.2732 \\
(0.4790)\end{array}$ & $\begin{array}{r}-1.2271^{*} \\
(0.4161)\end{array}$ & $\begin{array}{c}0.4395 \\
(0.3513)\end{array}$ \\
\hline $\mathrm{Fu}$ & $\begin{array}{c}-0.9489 \\
(2.4703)\end{array}$ & $\begin{array}{c}0.7197 \\
(1.4733)\end{array}$ & $\begin{array}{c}-1.6409 \\
(2.7241)\end{array}$ & $\begin{array}{c}-0.9173 \\
(1.7927)\end{array}$ & $\begin{array}{c}-0.8140 \\
(1.2379)\end{array}$ & $\begin{array}{r}2.0303^{*} \\
(0.7390)\end{array}$ \\
\hline
\end{tabular}

Notes: Demographic controls include black, Hispanic, education, age, number of children, whether has a disability, and whether a female head. Standard errors in parentheses. Asterisk indicates $\mathrm{p}<0.10$, two-tailed test.

ual transitions from one year to the next as the dependent variables. We focus on transitions into and out of $A F D C$ and transitions into and out of FSP Only. The models in table 2 control for the transition year and demographic characteristics of the individual.

\section{AFDC Exit}

We first examine exits from $A F D C$ (columns 1 and 2). AFDC recipients in states with a higher maximum ADFC benefit are less likely to exit to FSP Only. AFDC recipients in states with a higher unemployment rate are more likely to exit to FSP Only. Some waiver policies affect the rate of exit from $A F D C$. In states with no exemptions from the work requirement for very young children, AFDC recipients are more likely to exit $A F D C$ to FSP Only. Perhaps, participants are able to maintain noncash assistance (such as food stamps) even if they are no longer eligible for cash assistance or are unable to comply with the work requirements. Partial/partial sanctions, in contrast, are associated with a higher likelihood of leaving $A F D C$ completely (marginally significant). Finally, individuals in states that implemented time limits are more likely to leave $A F D C$ and not receive FSP benefits than individuals in states that had no time limit in place.

\section{AFDC Entrance}

The association between waiver policies and rates of entry into AFDC from FSP Only and from Neither are shown in columns 3 and 4 of table 2. In contrast to exits from $A F D C$, no state waiver policies are significantly associated with entering AFDC. FSP Only participants in states with an exemption for children zero to six months are marginally more likely to enter $A F D C$. Employment conditions and benefit levels are significantly associated with entry to AFDC, as one would expect. 


\section{FSP Only Exit and Entrance}

Columns 5 and 6 of table 2 focus on transitions from FSP Only to Neither and vice versa. As expected, the higher the unemployment rate, the less likely a recipient is to exit FSP Only and the more likely a nonrecipient is to enter (the latter result is not quite significant at the 0.10 level). State waiver policies affecting food stamp exit and entrance were likely to operate indirectly through affecting recipients' transitions into and out of $A F D C$ and directly by affecting the options available for meeting their family's needs. A number of waiver policies are linked to exits from FSP Only. Food stamp participants living in states with few exemptions from work requirements for parents of young children, and with severe sanctions for failing to meet the work requirements, are less likely to leave FSP Only and to move to no assistance than those living in states with less strict policies. If they live in a state with an expanded earnings disregard, which allows them to keep more income as they work their way off of welfare, they are more likely to exit to neither program. Not only do these associations not disappear with controls for demographic characteristics, but they are stronger than without such controls (not shown). These findings reflect cross-program interactions which are difficult to interpret.

A few public waiver policies are also linked to movement of non-recipients into FSP Only. In states that instituted a time limit, individuals are more likely to enter FSP Only (table 2, column 6). Likewise, in states that instituted full sanctions for initial and later violations of the requirements, individuals are significantly more likely to enter FSP Only. Perhaps people who are sanctioned sometimes exit $A F D C$, then reenter to FSP Only. Alternatively, they may be eligible for welfare but discouraged from applying or unwilling to meet the requirements for participation, so they enter FSP Only instead.

Nonrecipients in states with no exemptions from work for parents of very young children are less likely to enter FSP Only (table 2, column 6). This result is consistent with the story that FSP Only provides a transition off cash assistance rather than a route on. Individuals in states with a family cap are less likely to go from no program to the FSP only, though the effect is only marginally significant.
In sum, the transition analysis finds evidence that the types of waiver policies states implemented during the 1990s prior to TANF affected individual behavior regarding their receipt of cash and noncash assistance. In general, stricter policies were associated with more departures from $A F D C$ but fewer from FSP Only. The expanded earnings disregard was associated with greater departures from FSP Only. Entrances to AFDC were not significantly explained by public policies.

\section{Conclusions}

Returning to the first motivating question, macroeconomic conditions do appear to affect transitions from cash and noncash programs in roughly the same direction. Although not all the parameters are statistically significant, the logistic regression analysis finds as expected that a higher unemployment rate decreases the probability of exit from both program participation categories to Neither and increases the probability of entry from Neither to both program participation categories. What may be more surprising is that a higher unemployment rate increases the probability of a transition from AFDC participation to FSP Only. One might have thought that unfavorable macroeconomic conditions would keep people dependent on both programs. One interpretation is that in an environment where people are always entering and leaving cash assistance, transitions to the FSP Only state are substituting for leaving public assistance altogether.

With regard to the second motivating question, we find that changes to the AFDC program through waivers appear significantly to affect transition rates even for the FSP Only participation category. Indeed, we find several significant parameters on welfare waiver variables for transitions between the FSP Only category and Neither, but no corresponding significant parameters for transitions between the AFDC category and Neither. The FSP and cash welfare programs serve a partly overlapping population, so changes in conditions of any program participation state may in principle influence the probability of transition to, from, and between the remaining participation states. Further work is needed to extend this analysis to the post-1996 period, when even more significant program changes were instituted. 


\section{References}

Council of Economic Advisors. The Effects of Welfare Policy and the Economic Expansion on Welfare Caseloads: An Update. Washington DC, August 1999.

Figlio, D., and J. Ziliak. "Welfare Reform, the Business Cycle, and the Decline in AFDC Caseloads." Working paper, Joint Center for Poverty Research, March 1999.

Fitzgerald,J.,P.Gottschalk, and R. Moffitt. “An Analysis of Sample Attrition in Panel Data: The Michigan Panel Study of Income Dynamics." J. Human Resour. 33(Spring 1998):251-99.
Gleason, P., P. Schochet, and R. Moffitt. The Dynamics of Food Stamp Program Participation in the Early 1990s. Princeton NJ: Mathematica Policy Research Inc., 1998.

Moffitt, R. "The Effect of Pre-PRWORA Waivers on AFDC Caseloads and Female Earnings, Income, and Labor Force Behavior." Working paper, Joint Center for Poverty Research, May 1999.

Wallace, G., and R. Blank. "What Goes Up Must Come Down? Explaining Recent Changes in Public Assistance Caseloads.” Working paper, Joint Center for Poverty Research, February 1999. 